\title{
Postnatal Care Based on ICM's Global Standards among Nursing Students Studying in a Selected College in Delhi
}

\author{
Nusrat Nazir', Manju Chhugani', $\underline{\text { Somibala Thokchom }}^{3}$, Mikki Khan $^{4}$ \\ ${ }^{1}$ M.Sc., Obstetrical and Gynaecological Nusring, Srinagar, Jammu and Kashmir, India. \\ ${ }^{2}$ Dean, ${ }^{3,4}$ Assistant Professor, Rufaida College of Nursing, Jamia Hamdard, New Delhi, India. \\ DOI: https://doi.org/10.24321/2455.9318.202016
}

\section{I $\quad \mathbf{N} \quad \mathbf{F}$}

\author{
Corresponding Author: \\ Nusrat Nazir, Obstetrical and Gynaecological \\ Nusring, Srinagar, Jammu and Kashmir, India. \\ E-mail Id: \\ nusratnazir388@gmail.com \\ Orcid Id: \\ https://orcid.org/0000-0002-8451-9509 \\ How to cite this article: \\ Nazir N, Chhugani M, Thokchom S, Khan M. \\ Postnatal Care Based on ICM's Global Standards \\ among Nursing Students Studying in a Selected \\ College in Delhi. Int J Nurs Midwif Res 2020; \\ $7(2): 32-37$.
}

Date of Submission: 2020-06-04

Date of Acceptance: 2020-10-22

\section{$\begin{array}{llllllll}\mathbf{A} & \mathbf{B} & \mathbf{S} & \mathbf{T} & \mathbf{R} & \mathbf{A} & \mathbf{C} & \mathbf{T}\end{array}$}

Background: Postnatal period is considered as the most critical phase which can lead to various complications and even maternal deaths. Midwives and nurses have an important role to play in the postnatal care of a mother hence they must have exceptional knowledge and skill to address the complications that arise in mothers during postnatal period. The competence level of midwives and nurses must be earned by set criteria of ICM Global standards of Midwifery.

Objectives: To assess the knowledge and skills among nursing students in selected college of Delhi on Postnatal Care as per ICM Global Standards by using Checklist and Questionnaire and to find out an association of Knowledge and skill on postnatal care with selected demographic variables regarding ICM's Global standards.

Materials and Methods: A quantitative research approach with descriptive exploratory design was used to achieve the objectives of the study. Total enumerating sampling technique was employed to select 56 students of DGNM interns posted in postnatal wards of hospital. A structured questionnaire and checklist were formulated to assess the knowledge and skills of Nursing Students.

Result and Findings: The study showed that Maximum students i.e. $45(80.35 \%)$ had inadequate knowledge related to postnatal care of mother whereas $11(19.64 \%)$ nursing students had adequate knowledge. Maximum students i.e. 34 (61\%) had inadequate knowledge related to postnatal care of newborn whereas $22(39 \%)$ had adequate knowledge regarding the same. The calculated ' $r$ ' value was 0.32 ; value at degree of freedom (54) is 0.27 which is lower than 0.0 e ' $r$ ' 5 level of significance.

Conclusion: The study shows that the students need more emphasis on skill improvement. There is a need to up skill the existing skills of nursing students in order to provide comprehensive and prompt Nursing Care.

Keywords: Knowledge, Skill, Postnatal Care, ICM Global Standards, Nursing Students, Mother, Newborn 


\section{Introduction}

Postnatal care that ensures the health of girls and young mothers may be a universally conceded priority and is a basic right. Improving the survival and health of mothers and youngsters is central to the accomplishment of India's National Health goals below the National Health Mission (NHM) further as achievement of the Millennium Development Goals (SDG) 4 and 5.1.

In recent years, India has created vital progress in its pursuit to enhance maternal and kid health. As per Registrar General of India- Sample Registration System (RGI-SRS) report, Maternal Mortality magnitude relation (MMR) in India has decreased from 212 (2007-09) to a 130 (20142016) per a thousand live births. ${ }^{1}$ Similarly, as per the RGI - SRS Report 2014, the general mortality rate declined from sixty four to forty per a thousand live births. ${ }^{1}$

Both mothers and their newborns are vulnerable throughout the postpartum Period, particularly throughout the primary twenty four hours following the birth. Over 2 thirds of newborn deaths may occur by the tip of the primary week of delivery with up to half of all newborns deaths occurring in first twenty four hours. The major causes of maternal morbidity in India are postnatal hemorrhage, Abortion, infection and these may be prevented by Antenatal and Postpartum care. ${ }^{1}$

The ICM Global Standards for Midwifery Education (2010) are one of the essential pillars of ICM's efforts to strengthen midwifery worldwide by preparing fully qualified midwives to provide high quality, evidence-based health services for women, newborns, and childbearing families. ICM's pillars include updated core competencies for basic midwifery practice, midwifery education, midwifery regulation and strong midwifery associations. The education standards were developed in tandem with the update of the Essential Competencies for Basic Midwifery Practice (2010) as these competencies define the core content of any midwifery education programme. The education standards were also completed in harmony with midwifery standards of practice and regulation.

Postpartum period is a vulnerable time as most maternal and new born deaths occur throughout this era. The birth of the baby is one of the foremost overwhelming and emotional events that may occur in one's lifespan. The times and weeks following accouchement - the postpartum period - may be a crucial innovate in the lives of mothers and newborn babies but this is often the foremost neglected time for the supply of quality services. Lack of applicable care throughout this period might end in important pathological state and even death. Most maternal and newborn deaths occur throughout this period. Labor and accouchement are physically demanding, as is breastfeeding and looking out once a babe. It's thus vital that women sustain their strength and maintain their health as they befit life with their new baby and newer maternity.

Women within the postpartum period ought to maintain a diet, iron and B vitamin supplementation ought to additionally continue for three months after birth. Women who are breastfeeding need further food and may drink comfortable clean water. Medical examiners ought to pay longer on nutrition counseling with women are terribly slim and with adolescents who might have further info to assist them get a diet. Exploring less costly choices will be a useful a part of the counseling session. The act of birth is that the solely moment once each pain and pleasure converge in an exceedingly moment of your time. Women in the postnatal period need to maintain a balanced diet, just as they did during the baby's birth, the woman was a lady. When the baby is born, the lady is reworked in to a mother. This is often a revolutionary act for each newborns and mothers. ${ }^{2}$ The policies and programmers have mostly unnoticed this vital time, hindering efforts to meet the Millennium Development Goals (MDG"S) for maternal and newborns survival. Every year, four million infants die inside their initial month of life, representing nearly $40 \%$ of all deaths of kids below age 5.3.

It is counseled that each women endure a comprehensive visit in the primary 6 weeks after birth of newborn, In order to optimize postpartum take care of patients and to market continuation of care through a woman's period. The mother must adapt to multiple physical, social and psychological changes. She has to pass through the process of giving birth, comply with dynamic hormonal changes and learn to feed and take care of her newborn. Additionally being a time of joy and excitement, this "fourth trimester" will gift major challenges like lack of sleep, pain, depression, lack of concupiscence and incontinence. ${ }^{4}$

Like those with Hypertensive disorders of maternity or women at high risk of postnatal depression, follow-up one to 2 weeks after birth is usually recommended. This visit is a chance for the lady to enquire about her general health post delivery and also the implications of any complications for her future health.

\section{Materials and Methods}

In order to accomplish objectives of the study, a quantitative non-experimental research approach using exploratory descriptive research design was considered to be appropriate to assess the knowledge and skill on postnatal care based on ICM global standards among nursing students of selected nursing colleges of Delhi.

The duration of data collection was from $1^{\text {st }}$ October, 2019 to 15th October 2019. Population comprised of students from selected college of nursing in Delhi. Total enumerating 
sampling technique was used and a total of 56 students of the age group between 17-25 years were taken from selected college of nursing who had met the inclusion criteria for the study. A structured questionnaire and checklist was developed to assess the knowledge and skill on postnatal care based on ICM Global Standards among nursing students of selected Nursing colleges of Delhi. The independent research variable as postnatal care and dependent variables was knowledge and skill of nursing students on postnatal care .

Content validity of the tool was established by 11 experts in Nursing, and the tool was found to be relevant, clear and feasible. The reliability of the knowledge questionnaire was established by using KR-20 (Kuder Richardson 20) formula and the reliability coefficient was 0.84 . The reliability of the checklist was obtained by Inter-rater reliability was found to be "r" $=0.88$ and tool was found to be reliable.

\section{Result}

The data was organized in terms of the objectives and was presented under the following sections.

Table I.Frequency and Percentage distribution of Nursing Students by their demographic characteristics

\begin{tabular}{|c|c|c|}
\hline Sample Characteristics & Frequency & Percentage \\
\hline \multicolumn{3}{|l|}{ Age (in years) } \\
\hline $18-20$ & 9 & $16 \%$ \\
\hline $21-23$ & 47 & $84 \%$ \\
\hline $23-25$ & 0 & $0 \%$ \\
\hline Above 25 & 0 & $0 \%$ \\
\hline \multicolumn{3}{|l|}{ Education } \\
\hline Bachelor & 0 & $0 \%$ \\
\hline Diploma & 56 & $100 \%$ \\
\hline Masters & 0 & $0 \%$ \\
\hline Others (specify) & 0 & $0 \%$ \\
\hline \multicolumn{3}{|l|}{ Religion } \\
\hline Hindu & 51 & $91 \%$ \\
\hline Muslim & 0 & $0 \%$ \\
\hline Christian & 3 & $5 \%$ \\
\hline Sikh & 2 & $4 \%$ \\
\hline \multicolumn{3}{|l|}{ Gender } \\
\hline Male & 0 & $0 \%$ \\
\hline Female & 56 & $100 \%$ \\
\hline
\end{tabular}

Table 1, shows that, with regard to age wise distribution of the nursing students posted in postnatal ward, most of the students i.e. 47 (84\%) were in the age group of $21-23$ years of age, 9 (16\%) were in $18-20$ years of age. The educational status depicts that all the students i.e. 56 (100\%) were of diploma level. All the Nursing students were females.

Table 2(a). This section shows findings related to the knowledge score on postnatal care of mothers among nursing students

\begin{tabular}{|c|c|c|c|c|c|c|}
\hline $\begin{array}{c}\text { Varia- } \\
\text { bles }\end{array}$ & $\begin{array}{c}\text { Poss- } \\
\text { ible } \\
\text { range } \\
\text { of } \\
\text { scores }\end{array}$ & $\begin{array}{c}\text { Range } \\
\text { of } \\
\text { obta- } \\
\text { ined } \\
\text { scores }\end{array}$ & Mean & $\begin{array}{c}\text { Med- } \\
\text { ian }\end{array}$ & $\begin{array}{c}\text { Mo- } \\
\text { de }\end{array}$ & $\begin{array}{c}\text { Stan- } \\
\text { dard } \\
\text { devi- } \\
\text { ation }\end{array}$ \\
\hline $\begin{array}{c}\text { Know- } \\
\text { ledge } \\
\text { scores }\end{array}$ & $0-50$ & $26-43$ & 35.43 & 35.00 & 35 & 3.07 \\
\hline \multicolumn{2}{|l|}{ Maximum score=50. }
\end{tabular}

Table 2(b).Frequency and percentage distribution of nursing students on the basis of their level of knowledge regarding postnatal care of mother

\begin{tabular}{|c|c|c|}
\hline Knowledge level & Frequency & Percentage (\%) \\
\hline $\begin{array}{c}\text { Inadequate } \\
\text { knowledge (0-18) }\end{array}$ & 45 & $80.35 \%$ \\
\hline $\begin{array}{c}\text { Adequate } \\
\text { knowledge (19-25) }\end{array}$ & 11 & $19.64 \%$ \\
\hline
\end{tabular}

Table 2 (b), indicates the most of the nursing students i.e. $45(80.35 \%)$ had inadequate knowledge on postnatal care of mother and only 11 (19.36\%) had adequate knowledge regarding the postnatal care of mother (Figure 1).

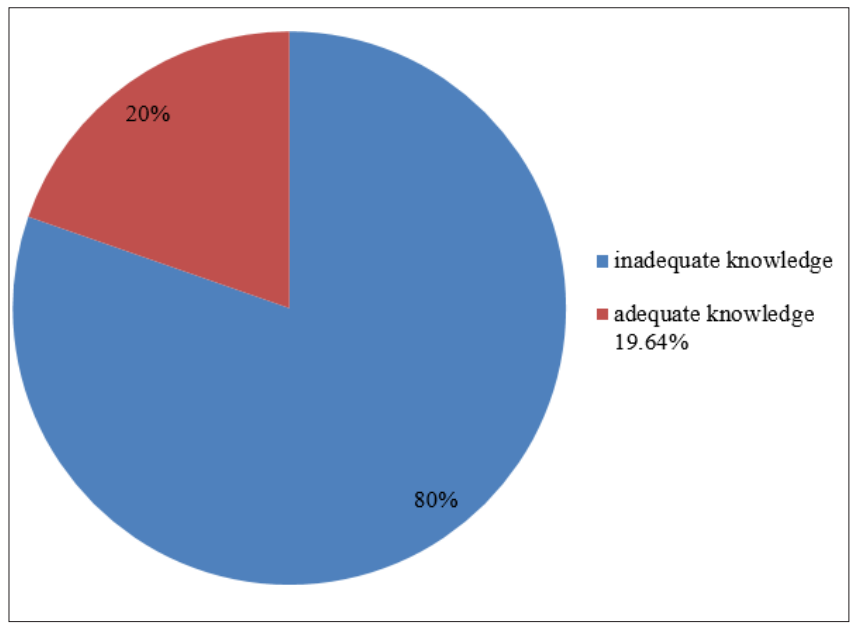

Figure I.A pie diagram showing the percentage distribution of the nursing students on the basis of their level of knowledge on the postnatal care of mother 
Table 2 (c).Frequency and percentage distribution of nursing students on the basis of their level of knowledge regarding postnatal care of newborn

\begin{tabular}{|c|c|c|}
\hline Knowledge level & Frequency & Percentage (\%) \\
\hline $\begin{array}{c}\text { Inadequate } \\
\text { knowledge (0-18) }\end{array}$ & 34 & $61 \%$ \\
\hline $\begin{array}{c}\text { Adequate } \\
\text { knowledge (19-25) }\end{array}$ & 22 & $39 \%$ \\
\hline
\end{tabular}

\section{Level of Knowledge}

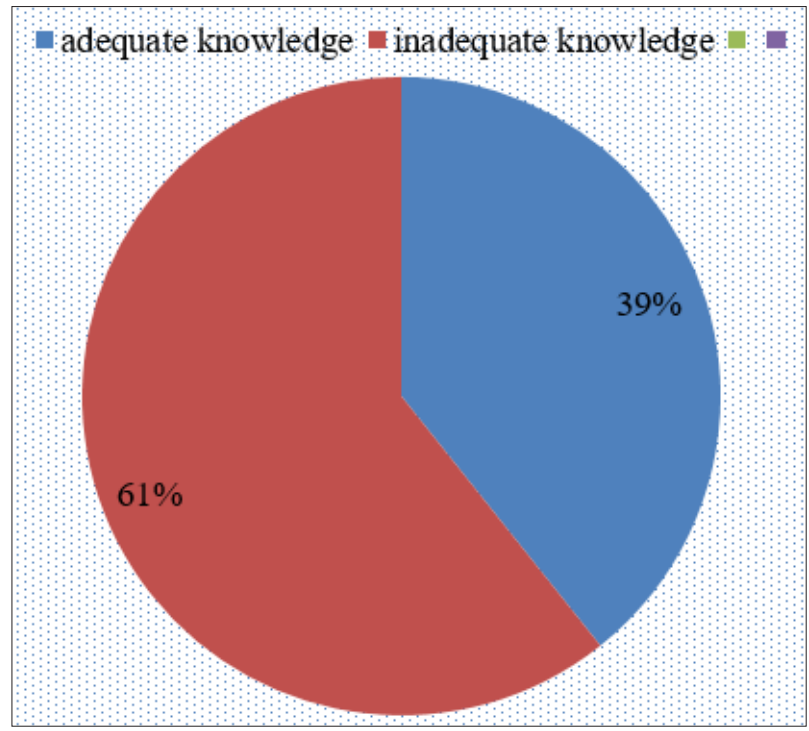

Figure 2.A pie diagram showing percentage distribution of the nursing students on the basis of their level of knowledge regarding postnatal care of newborn

Table 3.Frequency and percentage distribution of the nursing students on the basis of their level of practice

$(n=56)$

\begin{tabular}{|c|c|c|}
\hline Practice level & Frequency & Percentage (\%) \\
\hline $\begin{array}{c}\text { Inadequate practice } \\
(0-59)\end{array}$ & 41 & $73.21 \%$ \\
\hline $\begin{array}{c}\text { Adequate practice } \\
(60-80)\end{array}$ & 15 & $26.78 \%$ \\
\hline
\end{tabular}

Table 3, indicates that most of the nursing students i.e. 41 (73.21\%) had inadequate practice while only 15 (26.78\%) of the nursing students had adequate practice regarding postnatal care of newborn (Figure 3).

The data were analyzed to find out the relationship between the knowledge and practice scores and the selected factors i.e. (age) by computing Fisher's Exact Test values, where ever the frequencies in the contingency table were below 5 . The result of the Fisher's exact calculation are given below.

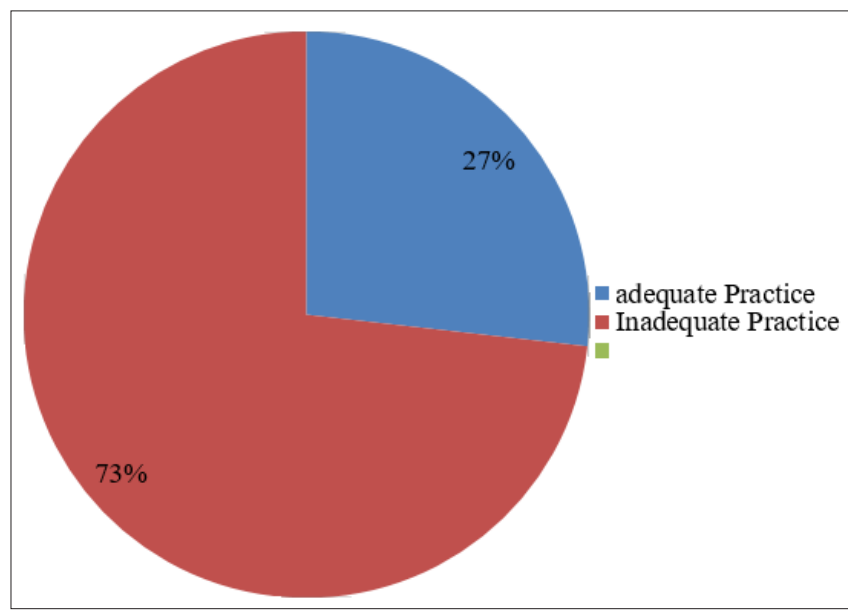

Figure 3.A pie diagram showing percentage distribution of the nursing students on the basis of their level of practice regarding postnatal care of newborn

Table 4.The association between the knowledge scores on postnatal care and age of nursing students

\begin{tabular}{|c|c|c|c|c|c|c|}
\hline $\begin{array}{c}\text { Nursing } \\
\text { Stud- } \\
\text { ents } \\
\text { posted } \\
\text { in post- } \\
\text { natal } \\
\text { ward }\end{array}$ & $\begin{array}{c}\text { Age } \\
\text { (in } \\
\text { years) }\end{array}$ & $\begin{array}{c}\text { Ade- } \\
\text { quate } \\
\text { kno- } \\
\text { wledge }\end{array}$ & $\begin{array}{c}\text { Inade- } \\
\text { quate } \\
\text { know- } \\
\text { ledge }\end{array}$ & Df & $\begin{array}{c}\text { Fish- } \\
\text { er's } \\
\text { exact } \\
\text { value }\end{array}$ & $\begin{array}{c}\text { p- } \\
\text { value }\end{array}$ \\
\hline & $18-20$ & 4 & 5 & 1 & 3.698 & 0.0241 \\
\hline & $21-23$ & 30 & 17 & & & \\
\hline
\end{tabular}

Fisher's exact value $=3.698, p \geq 0.05$.

Table 4, shows that the calculated Fisher's exact value was 3.698; the obtained $p$ value of 3.698 is 0.0241 which is higher than tabulated value at 0.05 level of significance, hence, there was no significant association between knowledge scores on Postnatal care and age of nursing students.

Mean, standard deviation and Pearson's coefficient of correlation between knowledge and practice scores of nursing students on postnatal care was computed.

Table 5.Findings related to relationship between knowledge and skill of nursing students on postnatal care

$(n=56)$

\begin{tabular}{|c|c|c|c|c|}
\hline Variables & Mean & $\begin{array}{c}\text { Standard } \\
\text { deviation }\end{array}$ & Df & ' $r$ ' value \\
\hline Knowledge & 35.43 & 3.07 & 54 & $0.32 *$ \\
\hline Practice & 54.07 & 9.19 & & \\
\hline${ }^{\prime} r^{\prime}(54)=0.25 \geq 0$ &
\end{tabular}

Table 5, shows that the calculated ' $r$ ' value was 0.32 ; the ' $r$ ' value at degree of freedom (54) is 0.25 was lower than 0.05 level of significance. This indicates that there is a 
significant relationship between practice and knowledge scores of the nursing students posted in postnatal ward.

Table 6.Area wise mean, modified mean, possible range of scores, obtained range of scores and rank order of knowledge scores obtained by nursing students on postnatal care of mother

$(n=56)$

\begin{tabular}{|c|c|c|c|}
\hline $\begin{array}{c}\text { Areas of postnatal care of } \\
\text { mother }\end{array}$ & Mean & $\begin{array}{c}\text { Modified } \\
\text { mean }\end{array}$ & $\begin{array}{c}\text { Rank } \\
\text { order }\end{array}$ \\
\hline Postnatal visits & 26 & 8.66 & I \\
\hline $\begin{array}{c}\text { Physiological changes in } \\
\text { postpartum period }\end{array}$ & 25.4 & 5.08 & II \\
\hline Lochia & 24.28 & 3.46 & V \\
\hline Harmonal contraceptives & 15.8 & 3.16 & VIII \\
\hline Homan's Sign & 19.33 & 3.22 & VII \\
\hline Family planning methods & 24.28 & 3.45 & VI \\
\hline Episiotomy & 21.4 & 0.62 & $\mathrm{X}$ \\
\hline Uterine changes & 22.15 & 3.68 & IV \\
\hline Postpartum exercises & 25 & 5 & III \\
\hline Puerperal sepsis & 16.16 & 2.69 & IX \\
\hline & & &
\end{tabular}

Table 6, shows that the highest ranked area of knowledge was the postnatal visits (8.66) and the least ranked area of knowledge was in puerperal sepsis (2.69). The descending order of knowledge scores in the various areas of postnatal care were postnatal visits (8.66), Physiological changes in postpartum period (5.08), postpartum exercises (5), uterine changes (3.68), Lochia (3.46), family planning methods (3.45), Homan's Sign (3.22), Harmonal contraceptives (3.16), puerperal sepsis (2.69) and Episiotomy (0.62) (Figure 13).

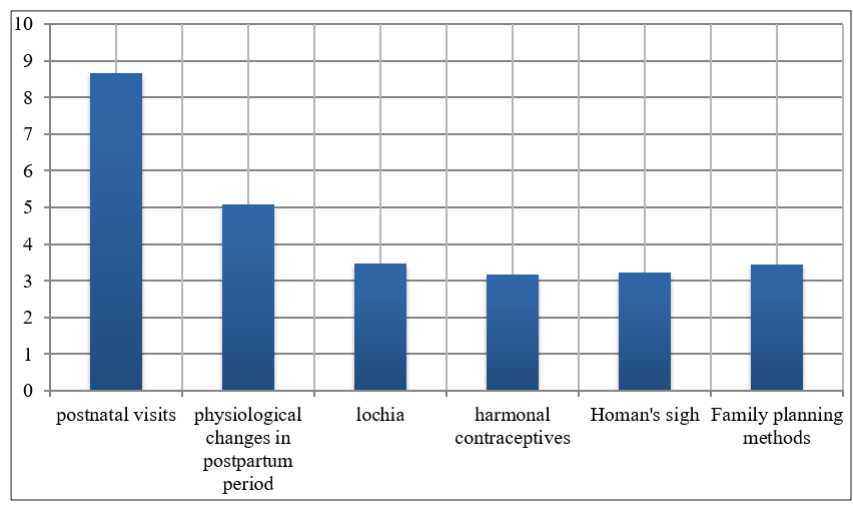

Figure 4.A bar diagram showing area wise comparison of knowledge areas on postnatal care of mother posted in postnatal wards

\section{Discussion}

In the present study, the findings reveals that the knowledge regarding postnatal visits got the highest mean rating of 8.66 and assessment of puerperal sepsis got the lowest mean rating of 2.69 in the maternal care and also in the newborn care aspect in present study, the findings revealed that "length of newborn got highest mean rating of 22 . Vaccination of newborn got the lowest mean rating of 2.04. The finding is supported by a study conducted by Jezreen. $\mathrm{C}$ on nursing students .Postnatal Care by Student Nurses in college of nursing, Benquet State University, Philippines The result showed that the practice of "vital signs" monitoring got the highest mean rating of 3.86 and assessment for the colour of "lochial discharges" got the lowest mean rating of 3.03 with a descriptive equivalence. It also revealed "breastfeeding" got the highest mean rating of 3.92 and prevention from bleeding got lowest mean rating of 3.64 in case of newborn.

Findings reveals that the knowledge and practice score related to newborn care, that mean knowledge score of nursing students was 35.43 with the $80.35 \%$ and $19.64 \%$ of the respondents have inadequate and adequate knowledge respectively. The mean practice score is 67.6 and $73.21 \%$ and $23.78 \%$ of the respondents have inadequate and adequate practice respectively. This Finding is supported by the study conducted by Bayisa Bereka Negussie13 on "Nurses and midwives" Knowledge and Practice of Essential Newborn Care and associated factors, Jimma Zone, Ethiopia. The result showed that the mean knowledge score of the study participants was 23.27 with $52.2 \%$ and $47.8 \%$ of the respondents had good and poor knowledge respectively. The mean score of practice was $32.82 \%, 51.1 \%$ and $48.9 \%$ of the respondents have good and poor practice respectively.

In present study, the findings reveal that the respondents with the modified mean of 5.08 i.e. $20 \%(n=56)$ are performing the assessment on physiological changes occurring in postnatal period i.e. (involution of uterus, fundal height measurements, vital signs). This finding was supported by study which was conducted by Bongani Robert Dlamini12 on "The Extent of Midwives Knowledge and Practices" during the provision of immediate postnatal care in Swaziland. The findings reveal that the $42.0 \%$ $(n=37)$ of respondents were not measuring maternal pulse during this postnatal period. While as the $43.2 \%$ of the respondents reported that they had monitored maternal respiratory rate, $56.8 \%$ did not see the importance of maternal respiratory rate monitoring at discharge. Uterine contraction assessment on every mother before discharge from hospital is vital, however, $44.5 \%$ ( $n=39)$ of the midwives did not include uterine contraction assessment in the package of care they offer to mothers on discharge. About $26.1 \%(n=23)$ reported that they did not conduct physical reported that they did not conduct physical examination on mothers at discharge.

\section{Conclusion}

The study concludes that there is a lack of knowledge 
and practice skills regarding postnatal care of mother and newborn care, which implies that the nursing leaders in education should give more focus on imparting the requisite knowledge and skills to the students during pre-service training and further senior staff nurses working in postnatal wards should mentor the student nurses posted in their wards. By doing this way, the student nurses will be better prepared for the future. ICM's Global standards should be a benchmark for nurse educators while educating the student nurses, which calls for the need of incorporating these standards in the midwifery curriculum.

\section{Conflict of Interest: None}

\section{References}

1. DAKSH - Participants Manual. Available from: http:// www.nhmmo.gov.in/webContent /MH/ Guidelines /02.01.16/ participants_3rd_Nov.pdf.

2. WHO recommendations on postnatal care of the mother and newborn, Geneva. Report No.: 9789241506649. 2013.

3. Chiral P, Purvi P, Kirti G et al. Knowledge, awareness, and practice of postnatal care among mothers. Indian Journal of Child Health 2017; 2(2): 83-85.

4. Kavitha P, Prasath AR, Krishnaraj P. A study to assess the knowledge regarding postnatal care among the mothers. International Journal of Current Pharmaceutical and Clinical Research 2012; 2(1): 1-2.

5. Bogren MU, van Teijlingen E, Berg M. Where midwives are not yet recognized: a feasibility study of professional midwives in Nepal. Midwifery 2013; 29(10): 1103-9.

6. World Health Statistics, Geneva. WHO, 2014.

7. Global Standards of Midwifery (2010)-Amended 2013 International Confederation of Midwives 67-72. Available from: http://www.internationalmidwives.org.

8. ICM Essential Competencies for Basic Midwifery Practice, Netherlands. 2019. Available from: www. internationalmidwives.org.

9. Ronsmans C, Graham WJ. Maternal mortality: who, when, where, and why. The Lancet Maternal Survival Series, 2006.

10. Polit F, Beck T. Essentials of Nursing Research. 7th ed. Lippincott, Philadelphia. 2009.

11. Jezreen C. Postnatal Care by Student Nurses. International Journal of Nursing Science 2015; 5(1): $35-40$

12. Bongani Robert Dlamini .The Extent of Midwives' Knowledge and Practices during the Provision of Immediate Postnatal Care in Swaziland. JOJ Nurse Health Care 2018; 18(8).

13. Negussie BB. Knowledge and Practice of Essential Newborn Care and Associated Factors among Nurses and Midwives Working at Health Centers in Jimma Zone, Ethopia. 2018; (13). 